\title{
Carbon skeleton doped with Co, N, S and P as efficient electrocatalyst for oxygen evolution reaction
}

\author{
Jiamei Cao ${ }^{1,2}$, Yongqiang Feng ${ }^{1,3^{*}}$, Baoyong $\mathrm{Liu}^{1,2}$ and Hongguang $\mathrm{Li}^{{ }^{* *}}$
}

\begin{abstract}
A new strategy for the preparation of highly efficient catalyst used in oxygen evolution reaction (OER) in alkaline media was developed. A Co-containing carbonitride polymer network (CoCN) was selected as a structural-directing template and a hypercross-linked polymer containing $S$ and $\mathrm{P}$, which formed on $\mathrm{CoCN}$ skeleton in situ, was used as a cover. After calcination at $450^{\circ} \mathrm{C}$ for $2 \mathrm{~h}$, an interconnected nanostructure was obtained and showed excellent activity and high stability for electrochemical water splitting. Trace amount of Co and other heteroatoms including $\mathrm{N}, \mathrm{S}, \mathrm{P}$ and the formed Co- $\mathrm{N}$ and $\mathrm{Co}-\mathrm{O}$ species are essential for the impressive catalysis performance. The calcination temperature of $450^{\circ} \mathrm{C}$ is optimal to the catalysis performance. These results suggest that $\mathrm{Co}$ in addition to heteroatom-doped (S, P) carbonitride could be used as a supplement and/or an alternative to noble metal oxides for water splitting.
\end{abstract}

Keywords: electrocatalyst, oxygen evolution, carbonitride, calcination, alkaline

\section{INTRODUCTION}

The aggravating energy and environment issues have stimulated intense focus on searching renewable and clean energy. Among various candidates proposed to date, hydrogen appears as a promising option. The stateof-the-art method for hydrogen generation is water splitting triggered either by electricity or light, which contains two complementary processes, i.e., the hydrogen evolution process [1] and the oxygen evolution reaction (OER) [2-4]. To overcome sluggish kinetics involved in OER relies on the development of efficient anodic electrocatalysts.

Up to date, the most active OER electrocatalysts are still precious metals and their oxides, such as $\mathrm{Ru}$, Ir and $\mathrm{RuO}_{2}$.
Their high costs and low abundance hindered their largescale application. Alternatively, Co-based catalysts have received much attention due to facile preparation and good performance, such as $\mathrm{Co}_{3} \mathrm{O}_{4}[5-10], \mathrm{Co}_{9} \mathrm{~S}_{8}[11,12]$, CoSe [13] or $\mathrm{CoSe}_{2}$ [14], $\mathrm{CoP}[15,16], \mathrm{Co}(\mathrm{OH})_{2}$ [17], $\mathrm{Co}_{x} \mathrm{~N}(x=2,3,4)[18]$ and various hybridized derivatives [19-29]. The development of metal-free OER catalyst $[2,3]$ is also purposed. However, up to now this method is concentrated on graphitic carbonitride $\left(\mathrm{g}-\mathrm{C}_{3} \mathrm{~N}_{4}\right)$ [30-33] and modified carbon nanostructures such as carbon nanotubes (CNTs) [33-35]. The performance of other metal-free materials which are entirely composed of lightweight elements is not good in most cases. To integrate the advantages of both transition metals and light-weight elements into one catalyst, a promising strategy containing carbon materials with metallic and/or heteroatomic dopants is proposed. In addition, the stability of the catalysts could be greatly improved due to the protection from the carbon materials in harsh conditions. Moreover, the performance of the hybridized materials could be further improved by the introduction of heteroatoms to modify the electronic structure of the adjacent carbon atoms.

We present the preparation of a new carbon-based catalyst doped with Co, N, S and P (Scheme 1a). Only trace level of Co $(<5 \%$ by mass) is detected in the final catalyst. The catalyst shows impressive performance in OER in alkaline media. To optimize the performance of the catalysts, we also investigate the influences of other transition metals and calcination conditions.

\section{EXPERIMENTAL SECTION}

\section{Materials}

All reagents were of analytical grade and used as received.

\footnotetext{
${ }^{1}$ State Key Laboratory of Solid Lubrication \& Laboratory of Clean Energy Chemistry and Materials, Lanzhou Institute of Chemical Physics, Chinese Academy of Sciences, Lanzhou 730000, China

${ }^{2}$ School of Materials Science and Engineering, Shaanxi University of Science \& Technology, Xi'an 710021, China

${ }^{3}$ University of Chinese Academy of Sciences, Beijing 100049, China

* Corresponding authors (emails: hgli@licp.cas.cn (Li H); fengyq@sust.edu.cn (Feng Y))
} 
a
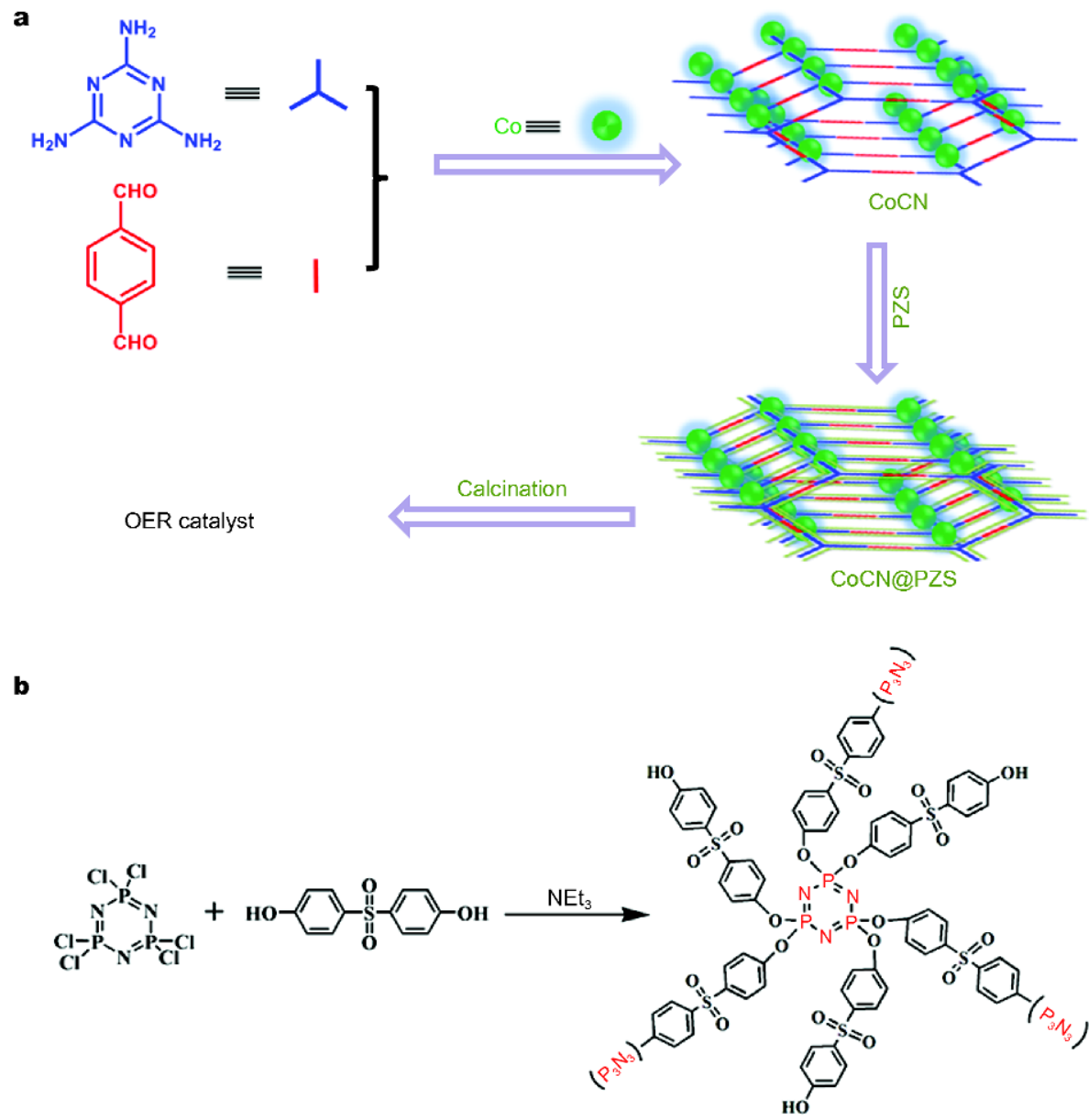

Scheme 1 Illustration of the synthetic route of the OER catalyst (a) and the hyper cross-linked polymer PZS (b).

Melamine (>99\%), terephthalaldehyde (>99\%), 4,4'-sulfonyldiphenol ( $>99 \%)$, phosphonitrilic chloride trimer $(>98 \%)$ were purchased from J\&K Chemical Reagent Co., Ltd. Cobalt nitrate hexahydrate $(>99 \%)$, nickel nitrate hexahydrate $(>98 \%)$ and copper (II) nitrate trihydrate ( $>98 \%)$ were obtained from Kermel Chemical Reagent Co., Ltd. Distilled water was utilized in all the experiments.

\section{Synthesis of MCN (M=Co, Ni, Cu)}

For the synthesis of $\mathrm{CoCN}, 4 \mathrm{mmol}$ of melamine and $7 \mathrm{mmol}$ of terephthalaldehyde were dissolved in $50 \mathrm{~mL}$ of dichloromethane (DCM). The mixture was stirred at $70^{\circ} \mathrm{C}$ for $30 \mathrm{~min}$, and then $6 \mathrm{mmol}$ of cobalt nitrate hexahydrate $\left(\mathrm{Co}\left(\mathrm{NO}_{3}\right)_{2} \cdot 6 \mathrm{H}_{2} \mathrm{O}\right)$ was added and stirred for $24 \mathrm{~h}$. Finally, the system was cooled down and the product was isolated by filtration, washed successively with distilled water and ethanol. The as-prepared product was further washed with distilled water in a Soxhlet apparatus for $24 \mathrm{~h}$, and dried at $55^{\circ} \mathrm{C}$ under vacuum until constant weight with a quantitative yield $(62 \%$ based on the conversion of melamine). $\mathrm{NiCN}$ and $\mathrm{CuCN}$ were prepared using similar procedure.

\section{Synthesis of MCN@PZS (M=Co, Ni, Cu)}

$\mathrm{CoCN}(400 \mathrm{mg}$ ) and $80 \mathrm{~mL}$ of methanol were mixed by sonication for $5 \mathrm{~min}$. Then another portion of methanol solution $(20 \mathrm{~mL})$ containing $300 \mathrm{mg}$ of phosphonitrilicchloride trimer and $675 \mathrm{mg}$ of 4, 4'-sulfonyldiphenol was added dropwise under stirring. After $5 \mathrm{~min}, 1 \mathrm{~mL}$ of triethylamine was added dropwise and the solution was further stirred for $18 \mathrm{~h}$. After that, the celadon precipitates were collected and washed with methanol three times and dried under vacuum at room temperature for $12 \mathrm{~h}$ to obtain CoCN@PZS. The preparation of NiCN@ PZS and CuCN@PZS were carried out in a similar pro- 
cedure. For CN@PZS the process was similar except the addition of metal nitrate salts.

\section{Synthesis of MCN@PZS-450 ${ }^{\circ} \mathrm{C}(\mathrm{M}=\mathrm{Co}, \mathrm{Ni}, \mathrm{Cu})$}

The dried powder of MCN@PZS $(\mathrm{M}=\mathrm{Co}, \mathrm{Ni}, \mathrm{Cu})$ was calcined at $450^{\circ} \mathrm{C}$ under $\mathrm{N}_{2}$ in a quartz tube furnace for $2 \mathrm{~h}$ with a ramping rate of $5^{\circ} \mathrm{C} \mathrm{min}^{-1}$. After cooling to room temperature, the product was collected. The obtained products were denoted as $\mathrm{MCN} @ \mathrm{PZS}-450^{\circ} \mathrm{C}(\mathrm{M}=$ $\mathrm{Co}, \mathrm{Ni}, \mathrm{Cu})$. To investigate the temperature effect, the temperature during calcination was also varied.

\section{Structural characterizations}

X-ray diffraction (XRD) patterns were obtained from a Rigaku D/max-2400 diffractometer (Japan) with $\mathrm{Cu} \mathrm{Ka}$ radiation $(\lambda=0.15418 \mathrm{~nm})$. The microstructure and morphology of materials were characterized using a transmission electron microscope (TEM; TF20) and a fieldemission scanning electron microscope (FESEM; JSM6701F, JEOL). Energy-dispersive X-ray spectroscope (EDS) attached to the FESEM was utilized to analyze the composition. X-ray photoelectron spectroscopy (XPS) was performed on an ESCALAB 250Xi and Raman spectra were recorded on HR-800, Jobin Yvon with a $514 \mathrm{~nm}$ Ar-ion laser as excitation source. Fourier transform-infrared spectroscopy (FTIR) was carried out on a VERTEX-70/70v spectrometer (Bruker Optics, Germany).

\section{Electrochemical measurements}

Electrochemical measurements were carried out using a three-electrode system at an electrochemical workstation (CHI660E, Shanghai Chenhua, China) in an aqueous solution containing $1.0 \mathrm{~mol} \mathrm{~L}^{-1} \mathrm{KOH}$. $\mathrm{Ag} / \mathrm{AgCl}$ was selected as the reference electrode and a Pt wire was used as the counter electrode. The working electrode was a glassy carbon with a diameter of $3 \mathrm{~mm}$. To prepare the working electrode for OER test, $4 \mathrm{mg}$ of the prepared catalyst was dispersed in $1 \mathrm{~mL}$ of ethanol and $10 \mu \mathrm{L}$ of nafion (5\%) by sonication for $5 \mathrm{~min}$. The suspension was then carefully dropped onto the electrode. The OER activity of the catalysts was measured by linear sweep voltammetry (LSV) from 1.20 to $1.80 \mathrm{~V} v s$. reversible hydrogen electrode (RHE) at a scan rate of $5 \mathrm{mV} \mathrm{s}^{-1}$. The essential stability tests were measured with cyclic voltammetry (CV) between 1.02 and $1.32 \mathrm{~V}$ at $100 \mathrm{mV} \mathrm{s}^{-1}$ for 1,000 cycles. The surface active area of CoCN@PZS- $450^{\circ} \mathrm{C}$ electrode was measured by $\mathrm{CV}$ from 1.02 to $1.32 \mathrm{~V}$ to further analyze their catalytic activity. All the measured potentials were calibrated with the RHE scale according to the Nernst equation $\left(E_{\mathrm{RHE}}=E_{\mathrm{Ag} / \mathrm{AgCl}}+0.059 \mathrm{pH}+0.197\right)$ without any $i R$-correction.

\section{RESULTS AND DISCUSSION}

A well-defined Co-doped carbonitride framework (i.e., $\mathrm{CoCN}$ ) was prepared first following a modified method [36]. In brief, melamine was reacted with terephthalaldehyde at the presence of trace cobalt nitrate via a one-step polycondensation reaction. SEM (Fig. 1a and Fig. S1) and TEM (Fig. S2) images show that the asobtained $\mathrm{CoCN}$ exhibits interconnected nanostructures. This structural feature makes $\mathrm{CoCN}$ an ideal catalyst, because the nanostructure can facilitate the exposure of the active sites. Without cobalt nitrate only micrometersized blocks are obtained (Fig. S3). Besides C, N, and O, evenly-distributed Co of about $1.15 \%$ (by atomic ratio) was detected (Fig. S4). The FTIR (Fig. 2) bands at 3,410 and $1,150 \mathrm{~cm}^{-1}$ belong to the stretching vibrations of the secondary amine $(-\mathrm{NH}-)$, indicating the formation of aminal linkages. The bands at 2,965 and $2,911 \mathrm{~cm}^{-1}$ can be assigned to the methyne $(-\mathrm{CH})$ groups, and the characteristic absorptions of triazinerings are observed at 1,562 and $1,468 \mathrm{~cm}^{-1}$ [37]. To enrich heteroatom-doping, hyper-crosslinked polymer (PZS [38]) was then coated on the surface of $\mathrm{CoCN}$ by in situ polymerization between phosphonitrilic chloridetrimer and 4, 4'-sulfonyldiphenol at the presence of triethylamine. With the PZS coating, the material surface becomes smooth (Fig. $1 \mathrm{~b}$ and Fig. S5a). Typical SEM and TEM images for the catalyst obtained at $450^{\circ} \mathrm{C}$ for $2 \mathrm{~h}\left(\mathrm{CoCN} @ \mathrm{PZS}-450^{\circ} \mathrm{C}\right)$ show the catalyst becomes porous after calcination in $\mathrm{N}_{2}$ atmosphere (Fig. 1c and Fig. S5b). EDS mapping reveals that all the elements are uniformly distributed in the sample (Fig. 1d, e, Fig. S6 and Table S1).

XPS spectra (Fig. S7) and high resolution XPS spectra (Fig. 3a-d and Fig. S8) show the Co $2 p$ peaks at about 780 and $786 \mathrm{eV}$ assigned to $\mathrm{Co}-\mathrm{N}$ specie, while the peaks at 796.5 and $804.6 \mathrm{eV}$ originate from $\mathrm{Co}-\mathrm{O}$ species. The $\mathrm{N}$ 1s spectra can be fit well with four kinds of $\mathrm{N}$ species. Peaks at about 398.8, 400.0, 401.0 and $404.9 \mathrm{eV}$ correspond to pyridinic nitrogen, pyrrolic nitrogen, graphitic nitrogen, and pyridinic $\mathrm{N}^{+}-\mathrm{O}^{-}$, respectively $[39,40]$. Besides these four peaks, an additional peak locates at $398.6 \mathrm{eV}$, which is ascribed to the pyridinic nitrogen or $\mathrm{P}=\mathrm{N} / \mathrm{P}-\mathrm{N}$ bond $[41,42]$. The $\mathrm{S} 2 \mathrm{p}$ region displays three peaks at 164.0, 165.2 and $168.3 \mathrm{eV}$, respectively, which are ascribed to $2 p_{3 / 2}$ and $2 p_{1 / 2}$ splitting of the $S 2 p$ spin orbital (-C-S-C-) and oxidized S, respectively. The P 2p spectrum shows two peaks at 132.7 and $133.9 \mathrm{eV}$, corresponding to $\mathrm{P}-\mathrm{C}$ and $\mathrm{P}-\mathrm{O}$, respectively. The $\mathrm{C} 1 \mathrm{~s}$ 

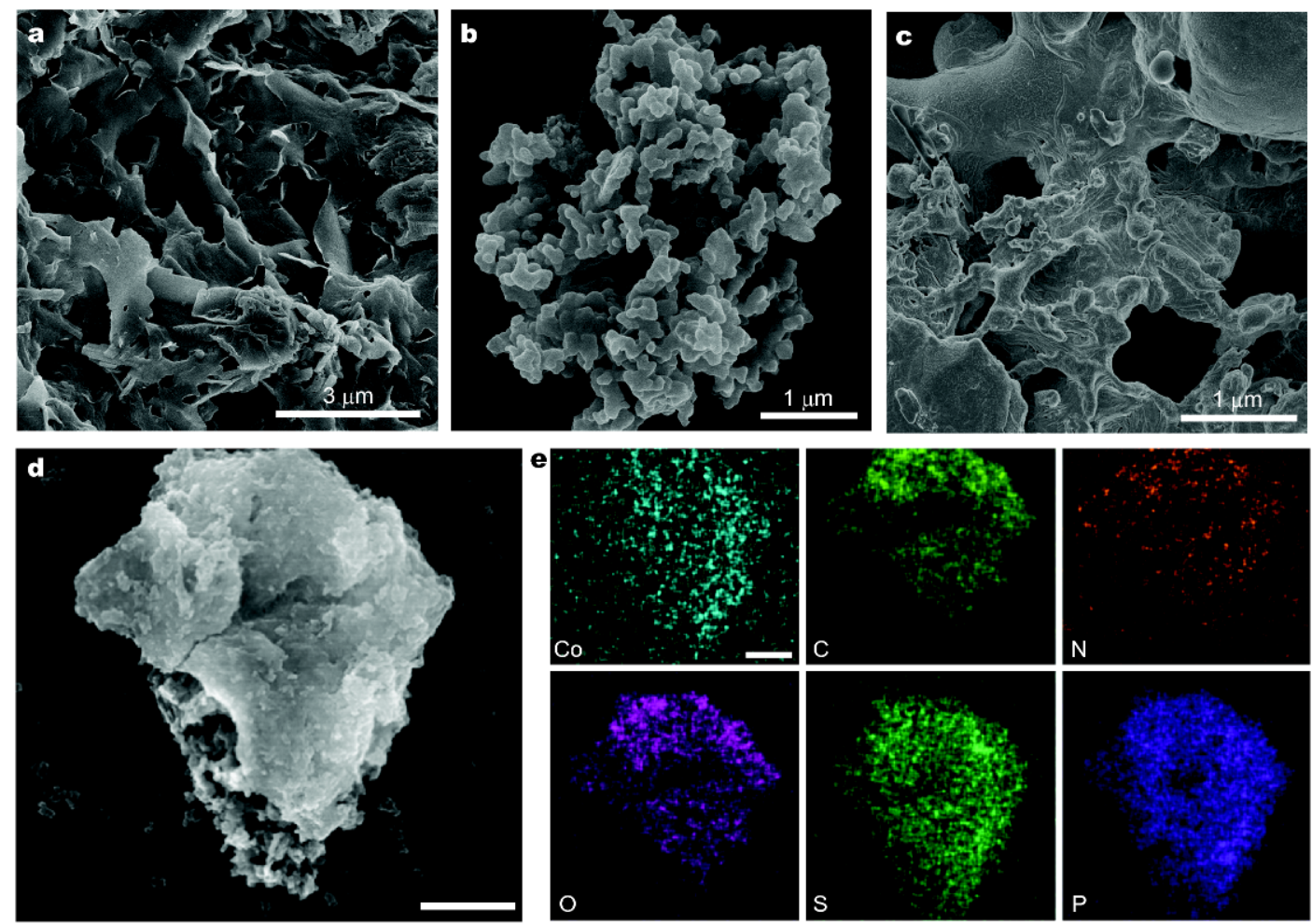

Figure 1 SEM images of (a) the as-synthesized CoCN, (b) CoCN@PZS, (c) CoCN@PZS-450 ${ }^{\circ} \mathrm{C}$. (d) The SEM image of CoCN@PZS-450 ${ }^{\circ} \mathrm{C}$ investigated by EDS mapping; (e) EDS mapping of Co, C, N, O, S and P. The scale bar in (d, e) is $500 \mathrm{~nm}$.

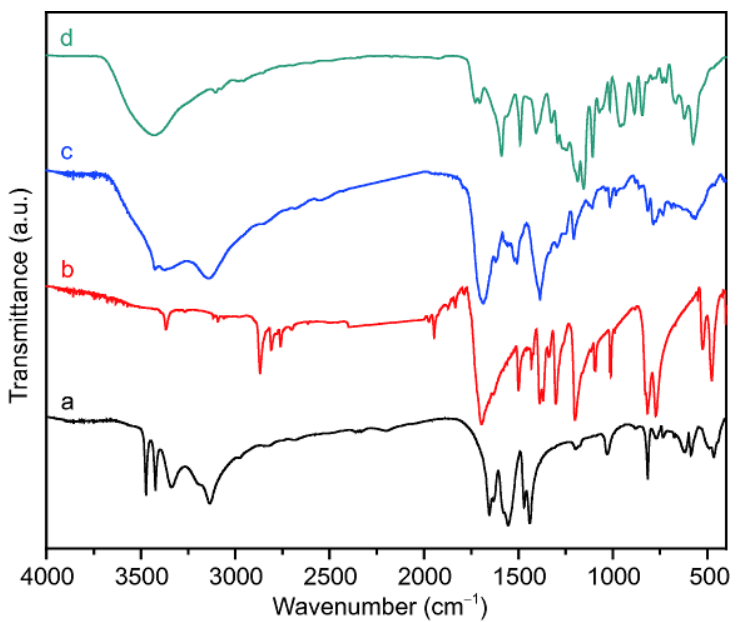

Figure 2 FTIR spectra of (a) melamine, (b) terephthalaldehyde, (c) CoCN and (d) CoCN@PZS (before calcination).

spectrum exhibits a $\mathrm{C}-\mathrm{C}$ peak at $284.7 \mathrm{eV}$, a $\mathrm{C}-\mathrm{N}$ peak at $285.8 \mathrm{eV}$ and a $\mathrm{C}=\mathrm{O}$ peak at $287.8 \mathrm{eV}$. For O 1s, the peaks centered at 531.5 and $533 \mathrm{eV}$ can be assigned to the $\mathrm{O} 1 \mathrm{~s}$ core levels in highly cross-linked PZS and adsorbed water, respectively. The atomic percentage of $\mathrm{C}, \mathrm{O}, \mathrm{Co}, \mathrm{N}, \mathrm{S}$ and
$\mathrm{P}$ is $73.99 \%, 14.13 \%, 0.80 \%, 4.60 \%, 1.18 \%$ and $5.30 \%$, respectively (Table $\mathrm{S} 1$ ).

The wide-angle XRD pattern (Fig. 3e) of the catalyst (CoCN@PZS $-450^{\circ} \mathrm{C}$ ) is similar to the standard patterns (JCPDF No. 76-1125). In Raman spectrum (Fig. 3f), two peaks at 1,341 and $1,598 \mathrm{~cm}^{-1}$ are assigned to $D$ and $G$ bands, respectively. The broad D-band indicates the presence of substantial defects or disorder-induced mode in the catalyst and the G-band is attributed to the graphitic structure. The structural defects are mainly caused by the doping of N, S, P and concomitant presence of Co atom. The high intensity ratio of D-band and G-band $\left(I_{\mathrm{D}} /\right.$ $I_{\mathrm{G}}$ ) suggests a large number of defects that might act as active catalytic sites [43].

$\mathrm{Cu}$ and $\mathrm{Ni}$ doped catalysts were prepared with the same procedure to investigate the influence of the type of doped metal on the structure and properties of the catalyst. The structural characterizations including SEM observations, XRD and Raman spectra are summarized in Fig. 4, and the contents of the elements both in the bulk and on the surface are listed in Table S1. EDS mapping of $\mathrm{CuCN} @ \mathrm{PZS}-450^{\circ} \mathrm{C}$ shows a significant increase of the metal content, which is up to $15.25 \%$ (Table S1). The 

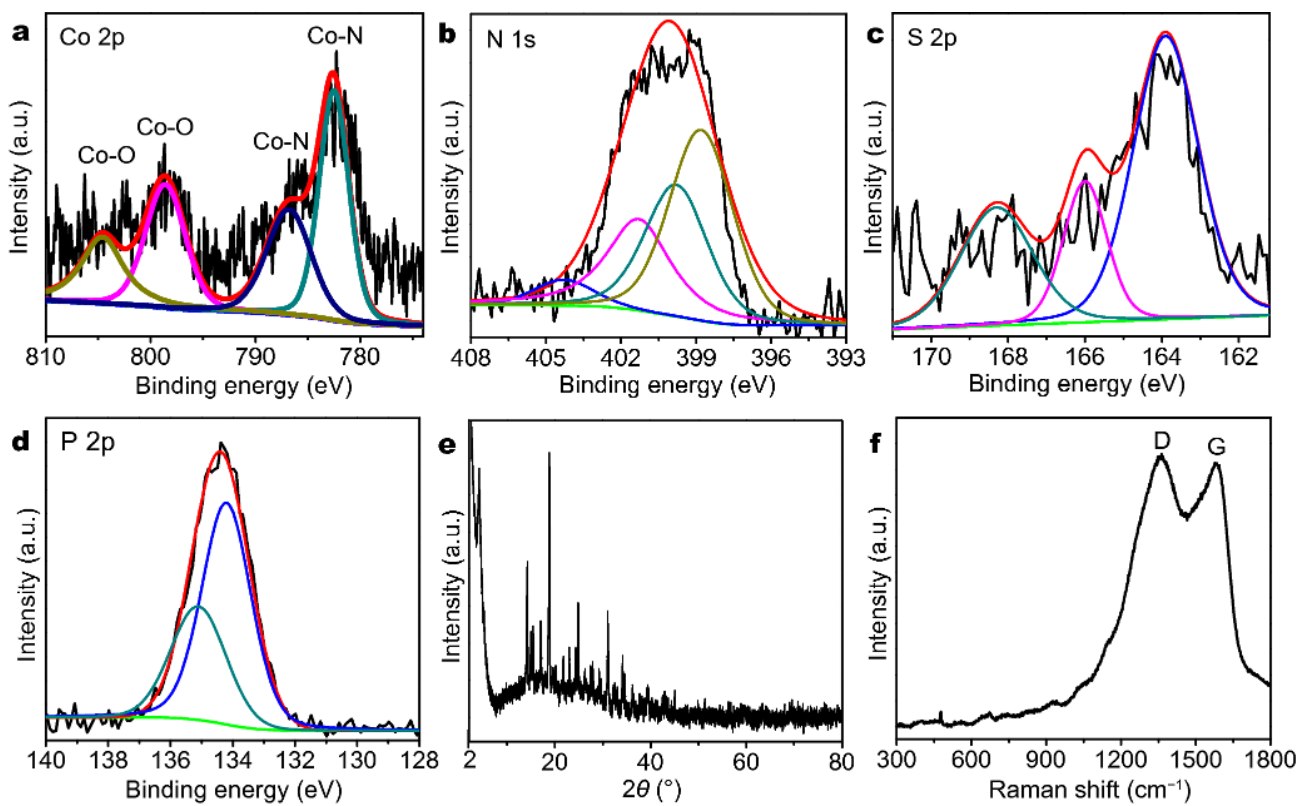

Figure 3 Structural characterizations of CoCN@PZS-450 ${ }^{\circ} \mathrm{C}$. High-resolution XPS spectra of (a) Co 2p, (b) N 1s, c) (S 2p and (d) P 2p. (e) XRD pattern; (f) Raman spectrum.
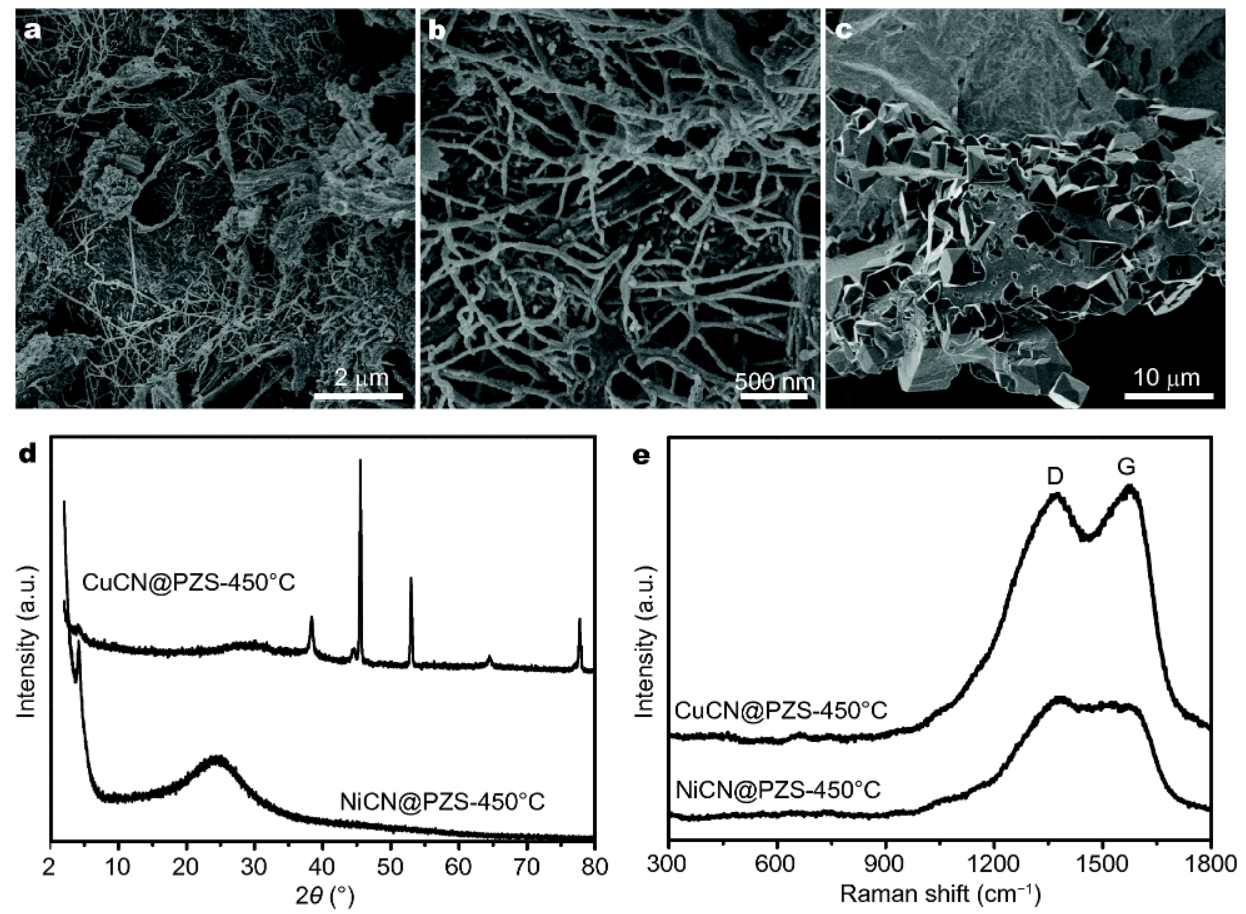

Figure 4 (a, b) SEM images at different magnifications of CuCN@PZS- $450^{\circ} \mathrm{C}$; (c) a typical SEM image of NiCN@PZS-450 ${ }^{\circ} \mathrm{C}$; (d) XRD pattern and (e) Raman spectra.

large content of $\mathrm{Cu}$ can be also verified by the sharp $\mathrm{Cu} 2 \mathrm{p}$ signal in XPS survey (Fig. S9), which gives an atomic percentage of $10.42 \%$ (Table S1). Besides C, the amount of S on the catalyst surface is high (Table S1). SEM images reveal the threadlike aggregates together with some amorphous structures (Fig. 4a, b). XRD pat- 

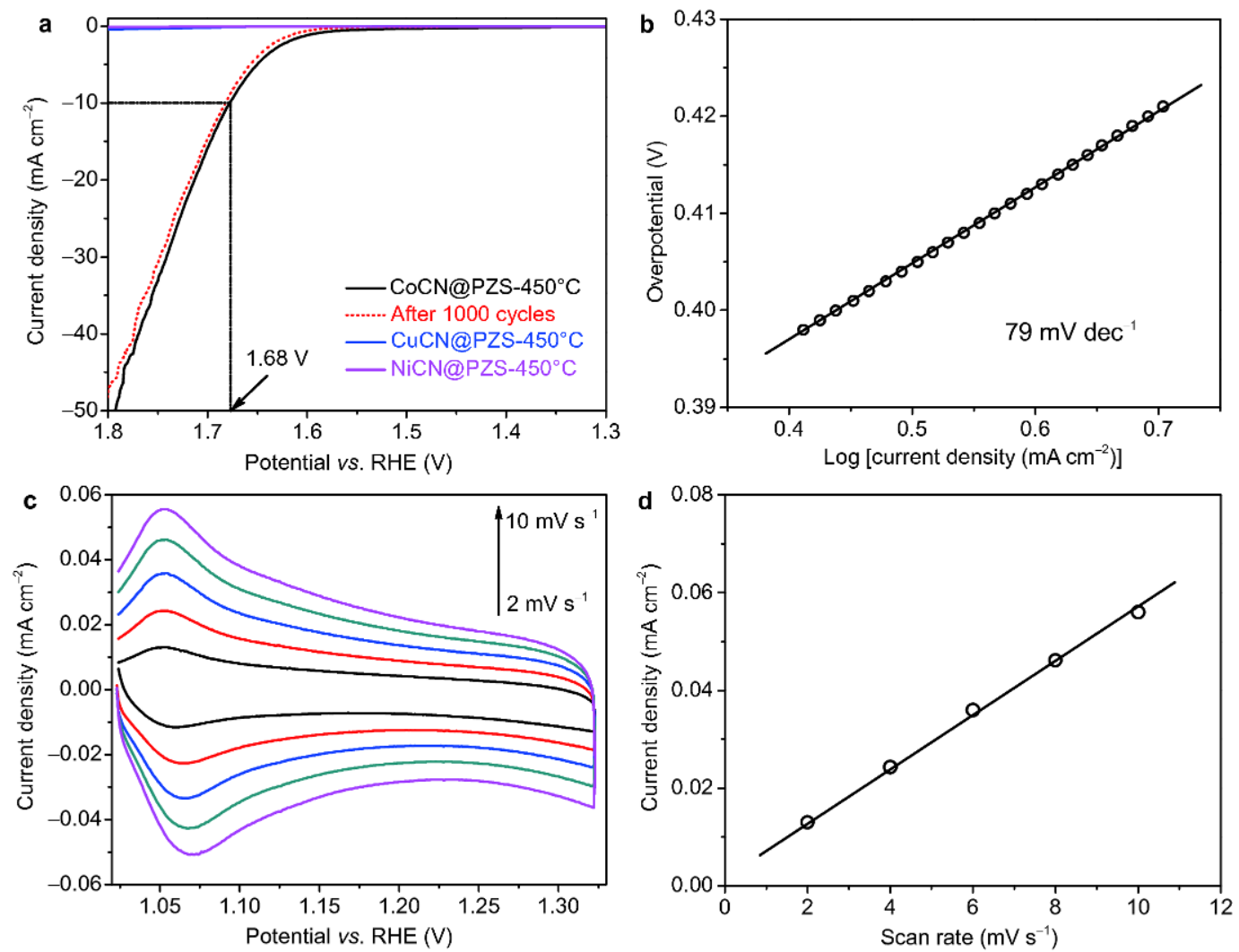

Figure 5 (a) OER polarization curves obtained in $1.0 \mathrm{~mol} \mathrm{~L}^{-1} \mathrm{KOH}$ at a scan rate of $5 \mathrm{mV} \mathrm{s}^{-1}$ for CoCN@PZS- $450^{\circ} \mathrm{C}, \mathrm{CuCN} @ \mathrm{PZS}-450^{\circ} \mathrm{C}$ and NiCN@PZS- $450^{\circ} \mathrm{C}$. The curve after 1,000 cycles is also included, which is presented as the dotted line. (b) Tafel plot of CoCN@PZS-450 ${ }^{\circ} \mathrm{C}$. The slope obtained from the linear fit (the solid line) is $79 \mathrm{mV} \mathrm{dec}^{-1}$; (c) CV of CoCN@PZS-450 ${ }^{\circ} \mathrm{C}$ measured at different scan rates in $1.0 \mathrm{~mol} \mathrm{~L}{ }^{-1} \mathrm{KOH}$; (d) plot of current density at $1.054 \mathrm{~V}$ as a function of the scan rate.

tern (Fig. 4d) shows an overlying of face-centred cubic lattice (JCPDF No.85-1326) and primitive cubic lattice (JCPDF No.74-1230), indicating good polycrystallinity. The Raman spectrum (Fig. 4e) looks similar with that of CoCN@PZS- $450^{\circ} \mathrm{C}$ with a slight decrease of $I_{\mathrm{D}} / I_{\mathrm{G}}$. In case of NiCN@PZS- $450^{\circ} \mathrm{C}$, the doping is unsuccessful and only trace of $\mathrm{Ni}(0.03 \%)$ is detected by EDS mapping (Table S1). XPS survey gives a slightly higher content of $\mathrm{Ni}$, which is different from CoCN@PZS- $450^{\circ} \mathrm{C}$ and $\mathrm{CuCN} @ \mathrm{PZS}-450^{\circ} \mathrm{C}$ where the metals tend to stay inside. However, the peak belonging to $\mathrm{Ni}$ is hardly seen due to the low content (0.27\%) (Fig. S10).

The catalysts' activities in OER were evaluated by LSV using a three-electrode system with a Pt foil as the counter electrode, $\mathrm{Ag} / \mathrm{AgCl}$ electrode as the reference electrode and a glassy carbon electrode loaded with catalyst as the working electrode in $1.0 \mathrm{~mol} \mathrm{~L}^{-1} \mathrm{KOH}$ aqueous solution. As shown in Fig. 5a, CoCN@PZS- $450^{\circ} \mathrm{C}$ was highly active for OER with a small overpotential of $450 \mathrm{mV}$ to achieve the current density of $10 \mathrm{~mA} \mathrm{~cm}^{-2}$ $\left(\eta_{10}\right)$. The small Tafel slope of $79 \mathrm{mV} \mathrm{dec}^{-1}$ (Fig. 5b) demonstrates the superior catalytic activity and efficient electron/mass transfer in CoCN@PZS- $450^{\circ} \mathrm{C}$. The performance of CoCN@PZS- $450^{\circ} \mathrm{C}$ is better than those reported recently under the same conditions $[44,45]$ and comparable to those performed in $0.1 \mathrm{~mol} \mathrm{~L}^{-1} \mathrm{KOH}$ aqueous solutions [46-49] (Table 1). Moreover, a very small decay of the current density after continuous $\mathrm{CV}$ scanning for 1,000 cycles demonstrates very good electrochemical stability, partially ascribed to the presence of an outer C-rich protecting layer.

In Fig. 5a, the performance of CoCN@PZS $-450^{\circ} \mathrm{C}$ is much better than its counterparts, i.e., CuCN@PZS$450^{\circ} \mathrm{C}$ and NiCN@PZS- $450^{\circ} \mathrm{C}$. Due to the ultralow current density in the range of high potentials $(>1.45 \mathrm{~V})$, the curves of $\mathrm{CuCN} @ \mathrm{PZS}-450^{\circ} \mathrm{C}$ and $\mathrm{NiCN} @ \mathrm{PZS}-450^{\circ} \mathrm{C}$ cannot be fitted to Tafel equation. Besides the intrinsic differences between the catalytic activity of $\mathrm{Co}, \mathrm{Cu}$ and $\mathrm{Ni}$, the different OER activity among these three catalysts could also be attributed to their different morphologies 
Table 1 Comparison of several recently reported highly active noble metal-free OER catalysts

\begin{tabular}{|c|c|c|c|c|c|}
\hline Catalyst & $\eta_{10}(\mathrm{mV} v s . \mathrm{RHE})$ & Tafel slope $\left(\mathrm{mV} \mathrm{dec}{ }^{-1}\right)$ & Electrolyte & Substrate & Ref. \\
\hline $\mathrm{Co}_{3} \mathrm{O}_{4}-35$ & 525 & Not available & $1 \mathrm{~mol} \mathrm{~L}^{-1} \mathrm{KOH}$ & Gold disk & {$[44]$} \\
\hline $\mathrm{Co}_{3} \mathrm{O}_{4} / \mathrm{SWCNT}$ & 594 & 104 & $1 \mathrm{~mol} \mathrm{~L}^{-1} \mathrm{KOH}$ & ITO & {$[45]$} \\
\hline CoCN@PZS-450C & 450 & 79 & $1 \mathrm{~mol} \mathrm{~L}^{-1} \mathrm{KOH}$ & Glassy carbon & This work \\
\hline $\mathrm{Co}_{3} \mathrm{O}_{4} / \mathrm{N}-\mathrm{PC}$ & 390 & 72 & $0.1 \mathrm{~mol} \mathrm{~L}^{-1} \mathrm{KOH}$ & Glassy carbon & {$[46]$} \\
\hline CYM-350 & $\sim 470$ & 68 & $0.1 \mathrm{~mol} \mathrm{~L}^{-1} \mathrm{KOH}$ & Glassy carbon & {$[47]$} \\
\hline N/Co-doped PCP-RGO & 430 & 292 & $0.1 \mathrm{~mol} \mathrm{~L}^{-1} \mathrm{KOH}$ & Glassy carbon & {$[48]$} \\
\hline N, S-codoped carbon nanosheets & $\sim 420$ & 59 & $0.1 \mathrm{~mol} \mathrm{~L}^{-1} \mathrm{KOH}$ & Glassy carbon & {$[49]$} \\
\hline
\end{tabular}
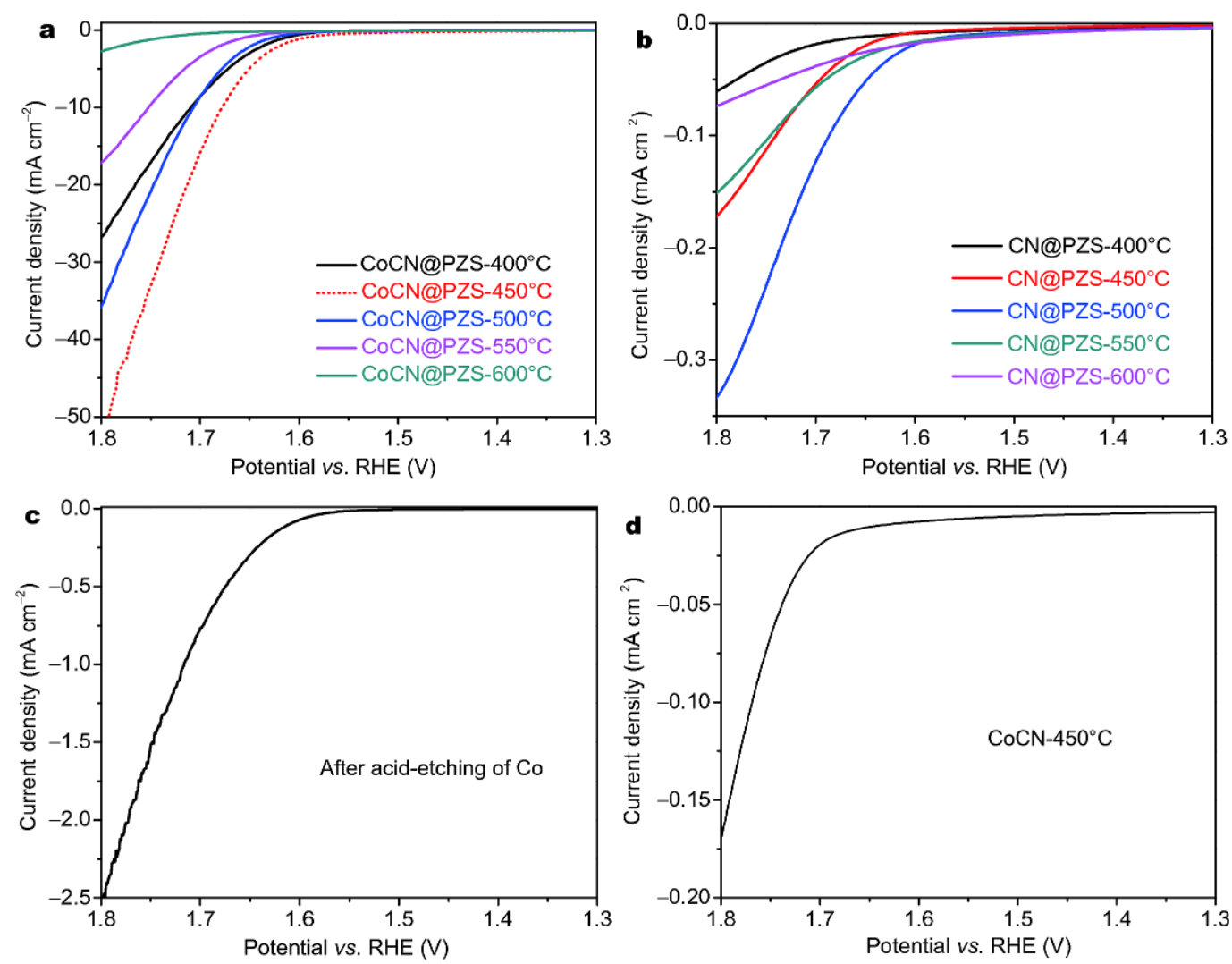

Figure 6 (a) OER polarization curves of CoCN@PZS calcinated at different temperatures. The curve of CoCN@PZS-450 ${ }^{\circ} \mathrm{C}$ which shows the best performance is highlighted by the dotted line. (b) OER polarization curves of the catalysts without Co doping (CN@PZS) calcinated at different temperatures. (c) OER polarization curve of CoCN@PZS- $450^{\circ} \mathrm{C}$ after removing Co by etching in $0.5 \mathrm{~mol} \mathrm{~L}^{-1} \mathrm{H}_{2} \mathrm{SO}_{4}$. (d) $\mathrm{OER}$ polarization curve of the catalyst without PZS coating calcinated at $450^{\circ} \mathrm{C}$. Measurements were carried out in $1.0 \mathrm{~mol} \mathrm{~L}^{-1} \mathrm{KOH}$ at a scan rate of $5 \mathrm{mV} \mathrm{s}^{-1}$.

and internal structures. Compared with the other two catalysts, CoCN@PZS- $450^{\circ} \mathrm{C}$ with sheet-like nanostructure shows high crystallinity and provides more active sites. The electrochemically active surface area (ECSA) can be evaluated on the basis of the electrochemical double-layer capacitance $\left(C_{\mathrm{dl}}\right)$ [50-52], since $C_{\mathrm{dl}}$ is proportional to the number of active sites of the catalysts.
Fig. $5 \mathrm{c}$ displays the CV curves of CoCN@PZS- $450^{\circ} \mathrm{C}$ in the range of $1.02-1.32 \mathrm{~V} v s$. RHE at a scan rate ranging from 2 to $10 \mathrm{mV} \mathrm{s}^{-1}$. A $C_{\mathrm{dl}}$ of $54 \mathrm{mF} \mathrm{cm}^{-2}$ can be calculated from the linear relationship of the current density against the scan rate shown in Fig. $5 \mathrm{~d}$. This high value implies that CoCN@PZS- $450^{\circ} \mathrm{C}$ has a large number of active sites, consistent with the excellent OER activity. 
The calcination temperature has an obvious influence on the activity of the catalyst. The sample prepared at $450^{\circ} \mathrm{C}$ shows the best performance, and lowering or raising the calcination temperature leads to fast decrease of the catalytic activity (Fig. 6a), indicating sample prepared at $450^{\circ} \mathrm{C}$ has the optimum doping content. Another contribution could be the structural changes induced by temperature. While SEM image of the sample obtained at $550^{\circ} \mathrm{C}$ shows that the catalyst still contains discrete and interconnected particles (Fig. S11), and the sample obtained at $600^{\circ} \mathrm{C}$ shows totally loose porous structure (Fig. S12).

In order to further reveal the mechanism of good electrocatalytic activity of our catalyst, control experiments were carried out. First, samples without Co-doping (CN@PZS) calcinated at different temperatures were prepared and the OER activities exhibit poor performance (Fig. 6b). On the other hand, when the doped Co in CoCN@PZS- $450^{\circ} \mathrm{C}$ was etched away by refluxing the catalyst in $0.5 \mathrm{~mol} \mathrm{~L}^{-1} \mathrm{H}_{2} \mathrm{SO}_{4}$ for $2 \mathrm{~h}$, the OER activity of the Co-free catalyst became eclipsed (Fig. 6c). These observations clearly demonstrated that the trace Co in the form of $\mathrm{Co}-\mathrm{O}$ and $\mathrm{Co}-\mathrm{N}$ species in the catalyst is indispensable to get good catalytic performance. We also investigated the role of $\mathrm{S}, \mathrm{P}$ and extra $\mathrm{N}$ introduced by coating PZS in the electrocatalytic process, and found that without PZS coating the catalyst exhibited unsatisfactory performance (Fig. 6d). Thus, it is clear that these heteroatoms in CoCN@PZS- $450^{\circ} \mathrm{C}$ could take a synergistic catalytic effect on the OER activity by changing the electronic structure and spin density of the adjacent carbon atoms [53-55].

\section{CONCLUSIONS}

In summary, we demonstrated that OER catalyst using a Co-containing carbonitride polymer network as a template and a hyper cross-linked polymer containing $S$ and $\mathrm{P}$ as a cover, can be facilely obtained by a simple in situ polymerization and subsequent calcination process. When used for electrochemical water splitting in $1.0 \mathrm{~mol} \mathrm{~L}^{-1} \mathrm{KOH}$ aqueous solution, the catalyst shows excellent activity and high stability. EDS mapping and XPS measurement show that the catalyst contains a catalytic amount of $\mathrm{Co}$ in $\mathrm{Co}-\mathrm{N}$ and $\mathrm{Co}-\mathrm{O}$ forms, which is essential for the impressive performance of the catalyst. Replacing Co by other transition metals such as $\mathrm{Cu}$ and $\mathrm{Ni}$ significantly lowers the activity of the catalyst. The performance of the catalyst is also affected by calcination procedure, with $450^{\circ} \mathrm{C}$ as the optimized temperature. The heteroatoms $(\mathrm{N}, \mathrm{S}$ and $\mathrm{P})$ could take a synergistic catalytic effect on the OER activity. These results suggest that Cocontaining, heteroatom-doped (S, P) carbonitride could be used as a supplement and/or an alternative to noble metal oxides for water splitting.

Received 26 August 2017; accepted 24 October 2017; published online 12 January 2018

1 Wang J, Xu F, Jin $\mathrm{H}$, et al. Non-noble metal-based carbon composites in hydrogen evolution reaction: fundamentals to applications. Adv Mater, 2017, 29: 1605838

2 Zheng $\mathrm{Y}$, Jiao $\mathrm{Y}$, Jaroniec $\mathrm{M}$, et al. Nanostructured metal-free electrochemical catalysts for highly efficient oxygen reduction. Small, 2012, 8: 3550-3566

3 Dai L, Xue Y, Qu L, et al. Metal-free catalysts for oxygen reduction reaction. Chem Rev, 2015, 115: 4823-4892

4 Zhu YP, Guo C, Zheng Y, et al. Surface and interface engineering of noble-metal-free electrocatalysts for efficient energy conversion processes. Acc Chem Res, 2017, 50: 915-923

5 Jiao F, Frei H. Nanostructured cobalt oxide clusters in mesoporous silica as efficient oxygen-evolving catalysts. Angew Chem Int Ed, 2009, 48: 1841-1844

6 Liang $\mathrm{Y}$, $\mathrm{Li} \mathrm{Y}$, Wang $\mathrm{H}$, et al. $\mathrm{Co}_{3} \mathrm{O}_{4}$ nanocrystals on graphene as a synergistic catalyst for oxygen reduction reaction. Nat Mater, 2011, 10: 780-786

7 Koza JA, He Z, Miller AS, et al. Electrodeposition of crystalline $\mathrm{Co}_{3} \mathrm{O}_{4}$-a catalyst for the oxygen evolution reaction. Chem Mater, 2012, 24: 3567-3573

8 Lu X, Zhao C. Highly efficient and robust oxygen evolution catalysts achieved by anchoring nanocrystalline cobalt oxides onto mildly oxidized multiwalled carbon nanotubes. J Mater Chem A, 2013, 1: 12053-12059

9 Sa YJ, Kwon K, Cheon JY, et al. Ordered mesoporous $\mathrm{Co}_{3} \mathrm{O}_{4}$ spinels as stable, bifunctional, noble metal-free oxygen electrocatalysts. J Mater Chem A, 2013, 1: 9992-10001

10 Singh SK, Dhavale VM, Kurungot S. Low surface energy plane exposed $\mathrm{Co}_{3} \mathrm{O}_{4}$ nanocubes supported on nitrogen-doped graphene as an electrocatalyst for efficient water oxidation. ACS Appl Mater Interfaces, 2015, 7: 442-451

11 Cao X, Zheng X, Tian J, et al. Cobalt sulfide embedded in porous nitrogen-doped carbon as a bifunctional electrocatalyst for oxygen reduction and evolution reactions. Electrochim Acta, 2016, 191: 776-783

12 Long J, Gong Y, Lin J. Metal-organic framework-derived $\mathrm{Co}_{9} \mathrm{~S}_{8} @$ CoS@CoO@C nanoparticles as efficient electro- and photo-catalysts for the oxygen evolution reaction. J Mater Chem A, 2017, 5: 10495-10509

13 Liao M, Zeng G, Luo T, et al. Three-dimensional coral-like cobalt selenide as an advanced electrocatalyst for highly efficient oxygen evolution reaction. Electrochim Acta, 2016, 194: 59-66

14 Ren X, Ge R, Zhang Y, et al. Cobalt-borate nanowire array as a high-performance catalyst for oxygen evolution reaction in nearneutral media. J Mater Chem A, 2017, 5: 7291-7294

15 Liu M, Li J. Cobalt phosphide hollow polyhedron as efficient bifunctional electrocatalysts for the evolution reaction of hydrogen and oxygen. ACS Appl Mater Interfaces, 2016, 8: 2158-2165

16 Xie L, Zhang R, Cui L, et al. High-performance electrolytic oxygen evolution in neutral media catalyzed by a cobalt phosphate nanoarray. Angew Chem Int Ed, 2017, 56: 1064-1068 
17 Subbaraman R, Tripkovic D, Chang KC, et al. Trends in activity for the water electrolyser reactions on $3 \mathrm{~d} \mathrm{M}(\mathrm{Ni}, \mathrm{Co}, \mathrm{Fe}, \mathrm{Mn}) \mathrm{hydr}$ (oxy)oxide catalysts. Nat Mater, 2012, 11: 550-557

18 Chen $\mathrm{P}, \mathrm{Xu} \mathrm{K}$, Tong $\mathrm{Y}$, et al. Cobalt nitrides as a class of metallic electrocatalysts for the oxygen evolution reaction. Inorg Chem Front, 2016, 3: 236-242

19 Chen S, Qiao SZ. Hierarchically porous nitrogen-doped graphene$\mathrm{NiCo}_{2} \mathrm{O}_{4}$ hybrid paper as an advanced electrocatalytic watersplitting material. ACS Nano, 2013, 7: 10190-10196

20 Shi $\mathrm{H}$, Zhao G. Water oxidation on spinel $\mathrm{NiCo}_{2} \mathrm{O}_{4}$ nanoneedles anode: microstructures, specific surface character, and the enhanced electrocatalytic performance. J Phys Chem C, 2014, 118: 25939-25946

21 Rosen J, Hutchings GS, Jiao F. Ordered mesoporous cobalt oxide as highly efficient oxygen evolution catalyst. J Am Chem Soc, 2013, 135: 4516-4521

22 Cai P, Huang J, Chen J, et al. Oxygen-containing amorphous cobalt sulfide porous nanocubes as high-activity electrocatalysts for the oxygen evolution reaction in an alkaline/neutral medium. Angew Chem Int Ed, 2017, 56: 4858-4861

23 Mendoza-Garcia A, Su D, Sun S. Sea urchin-like cobalt-iron phosphide as an active catalyst for oxygen evolution reaction. Nanoscale, 2016, 8: 3244-3247

24 Miyahara Y, Miyazaki K, Fukutsuka T, et al. Strontium cobalt oxychlorides: enhanced electrocatalysts for oxygen reduction and evolution reactions. Chem Commun, 2017, 53: 2713-2716

25 Al-Mamun M, Wang Y, Liu P, et al. One-step solid phase synthesis of a highly efficient and robust cobalt pentlandite electrocatalyst for the oxygen evolution reaction. J Mater Chem A, 2016, 4: 18314-18321

26 Zhuang L, Ge L, Yang Y, et al. Ultrathin iron-cobalt oxide nanosheets with abundant oxygen vacancies for the oxygen evolution reaction. Adv Mater, 2017, 29: 1606793

27 Tang C, Wang B, Wang HF, et al. Defect engineering toward atomic Co- $\mathrm{N}_{x}-\mathrm{C}$ in hierarchical graphene for rechargeable flexible solid Zn-air batteries. Adv Mater, 2017, 29: 1703185

28 Pan T, Liu H, Ren G, et al. Metal-free porous nitrogen-doped carbon nanotubes for enhanced oxygen reduction and evolution reactions. Sci Bull, 2016, 61: 889-896

29 Bau VM, Bo X, Guo L. Nitrogen-doped cobalt nanoparticles/nitrogen-doped plate-like ordered mesoporous carbons composites as noble-metal free electrocatalysts for oxygen reduction reaction. J Energy Chem, 2017, 26: 63-71

30 Zheng Y, Jiao Y, Chen J, et al. Nanoporous graphitic- $\mathrm{C}_{3} \mathrm{~N}_{4} @$ carbon metal-free electrocatalysts for highly efficient oxygen reduction. J Am Chem Soc, 2011, 133: 20116-20119

31 Liang J, Zheng Y, Chen J, et al. Facile oxygen reduction on a threedimensionally ordered macroporous graphitic $\mathrm{C}_{3} \mathrm{~N}_{4} /$ carbon composite electrocatalyst. Angew Chem Int Ed, 2012, 51: 3892-3896

32 Ma TY, Dai S, Jaroniec M, et al. Graphitic carbon nitride nanosheet-carbon nanotube three-dimensional porous composites as high-performance oxygen evolution electrocatalysts. Angew Chem Int Ed, 2014, 53: 7281-7285

33 Qiu Y, Xin L, Jia F, et al. Three-dimensional phosphorus-doped graphitic- $\mathrm{C}_{3} \mathrm{~N}_{4}$ self-assembly with $\mathrm{NH}_{2}$-functionalized carbon composite materials for enhanced oxygen reduction reaction. Langmuir, 2016, 32: 12569-12578

34 Gong K, Du F, Xia Z, et al. Nitrogen-doped carbon nanotube arrays with high electrocatalytic activity for oxygen reduction. Science, 2009, 323: 760-764
35 Li L, Yang H, Miao J, et al. Unraveling oxygen evolution reaction on carbon-based electrocatalysts: effect of oxygen doping on adsorption of oxygenated intermediates. ACS Energy Lett, 2017, 2: 294-300

36 Schwab MG, Fassbender B, Spiess HW, et al. Catalyst-free preparation of melamine-based microporous polymer networks through schiff base chemistry. J Am Chem Soc, 2009, 131: 72167217

37 Li G, Zhang B, Yan J, et al. The cost-effective synthesis of furanand thienyl-based microporous polyaminals for adsorption of gases and organic vapors. Chem Commun, 2016, 52: 1143-1146

38 Yang S, Peng L, Huang P, et al. Nitrogen, phosphorus, and sulfur Co-doped hollow carbon shell as superior metal-free catalyst for selective oxidation of aromatic alkanes. Angew Chem Int Ed, 2016, 55: $4016-4020$

39 Wei J, Hu Y, Liang Y, et al. Nitrogen-doped nanoporous carbon/ graphene nano-sandwiches: synthesis and application for efficient oxygen reduction. Adv Funct Mater, 2015, 25: 5768-5777

40 Zhong H, Wang J, Zhang Y, et al. ZIF-8 derived graphene-based nitrogen-doped porous carbon sheets as highly efficient and durable oxygen reduction electrocatalysts. Angew Chem Int Ed, 2014, 53: $14235-14239$

41 Razmjooei F, Singh KP, Song MY, et al. Enhanced electrocatalytic activity due to additional phosphorous doping in nitrogen and sulfur-doped graphene: a comprehensive study. Carbon, 2014, 78: 257-267

42 Wang $\mathrm{C}$, Sun L, Zhou Y, et al. P/N co-doped microporous carbons from $\mathrm{H}_{3} \mathrm{PO}_{4}$-doped polyaniline by in situ activation for supercapacitors. Carbon, 2013, 59: 537-546

43 Bayatsarmadi B, Zheng Y, Tang Y, et al. Significant enhancement of water splitting activity of $\mathrm{N}$-carbon electrocatalyst by trace level Co doping. Small, 2016, 12: 3703-3711

44 Tüysüz $\mathrm{H}$, Hwang YJ, Khan SB, et al. Mesoporous $\mathrm{Co}_{3} \mathrm{O}_{4}$ as an electrocatalyst for water oxidation. Nano Res, 2013, 6: 47-54

$45 \mathrm{Wu}$ J, Xue $\mathrm{Y}$, Yan $\mathrm{X}$, et al. $\mathrm{Co}_{3} \mathrm{O}_{4}$ nanocrystals on single-walled carbon nanotubes as a highly efficient oxygen-evolving catalyst. Nano Res, 2012, 5: 521-530

46 Hou $\mathrm{Y}, \mathrm{Li} \mathrm{J}$, Wen $\mathrm{Z}$, et al. $\mathrm{Co}_{3} \mathrm{O}_{4}$ nanoparticles embedded in nitrogen-doped porous carbon dodecahedrons with enhanced electrochemical properties for lithium storage and water splitting. Nano Energy, 2015, 12: 1-8

47 Guo Y, Tong Y, Chen P, et al. Engineering the electronic state of a perovskite electrocatalyst for synergistically enhanced oxygen evolution reaction. Adv Mater, 2015, 27: 5989-5994

48 Hou Y, Wen Z, Cui S, et al. An advanced nitrogen-doped graphene/cobalt-embedded porous carbon polyhedron hybrid for efficient catalysis of oxygen reduction and water splitting. Adv Funct Mater, 2015, 25: 872-882

49 Qu K, Zheng Y, Dai S, et al. Graphene oxide-polydopamine derived N, S-codoped carbon nanosheets as superior bifunctional electrocatalysts for oxygen reduction and evolution. Nano Energy, 2016, 19: 373-381

50 Kong D, Wang $\mathrm{H}, \mathrm{Lu} \mathrm{Z}$, et al. $\mathrm{CoSe}_{2}$ nanoparticles grown on carbon fiber paper: an efficient and stable electrocatalyst for hydrogen evolution reaction. J Am Chem Soc, 2014, 136: 4897-4900

51 Jiang J, Li Y, Liu J, et al. Recent advances in metal oxide-based electrode architecture design for electrochemical energy storage. Adv Mater, 2012, 24: 5166-5180

52 Tian J, Liu Q, Asiri AM, et al. Self-supported nanoporous cobalt phosphide nanowire arrays: an efficient 3D hydrogen-evolving 
cathode over the wide range of $\mathrm{pH}$ 0-14. J Am Chem Soc, 2014, 136: $7587-7590$

53 Gao H, Pan J, Han D, et al. Facile synthesis of microcellular foam catalysts with adjustable hierarchical porous structure, acid-base strength and wettability for biomass energy conversion. J Mater Chem A, 2015, 3: 13507-13518

54 Liu ZW, Peng F, Wang HJ, et al. Phosphorus-doped graphite layers with high electrocatalytic activity for the $\mathrm{O}_{2}$ reduction in an alkaline medium. Angew Chem Int Ed, 2011, 50: 3257-3261

55 Zhang C, Mahmood N, Yin H, et al. Synthesis of phosphorusdoped graphene and its multifunctional applications for oxygen reduction reaction and lithium ion batteries. Adv Mater, 2013, 25: 4932-4937

Acknowledgements This work was financially supported by the National Natural Science Foundation of China (21603243, 21402215 and 61474124), the Natural Science Foundation of Gansu Province (1606RJZA112) and the Natural science research project of Education
Department of Shaanxi Province (17JK0093).

Author contributions Cao J performed the main part of the experiment and wrote the draft. Liu B contributed to the FTIR and XPS measurements. Feng Y and $\mathrm{Li} \mathrm{H}$ designed the project, discussed the results and revised the paper.

Conflict of interest The authors declare that they have no conflict of interest.

Supplementary information Additional SEM and TEM images of CoCN and the carbonitride prepared at the absence of cobalt nitrate, EDS mapping of CoCN, TEM images of CoCN@PZS and CoCN@PZS$450^{\circ} \mathrm{C}$, EDS analyses and XPS spectra for CoCN@PZS- $450^{\circ} \mathrm{C}$, CuCN@PZS-450 ${ }^{\circ} \mathrm{C}$ and NiCN@PZS-450 $0^{\circ} \mathrm{C}$, SEM images of CoCN@PZS calcinated at $550^{\circ} \mathrm{C}$ and $600^{\circ} \mathrm{C}$ are available in the online version of the paper. 

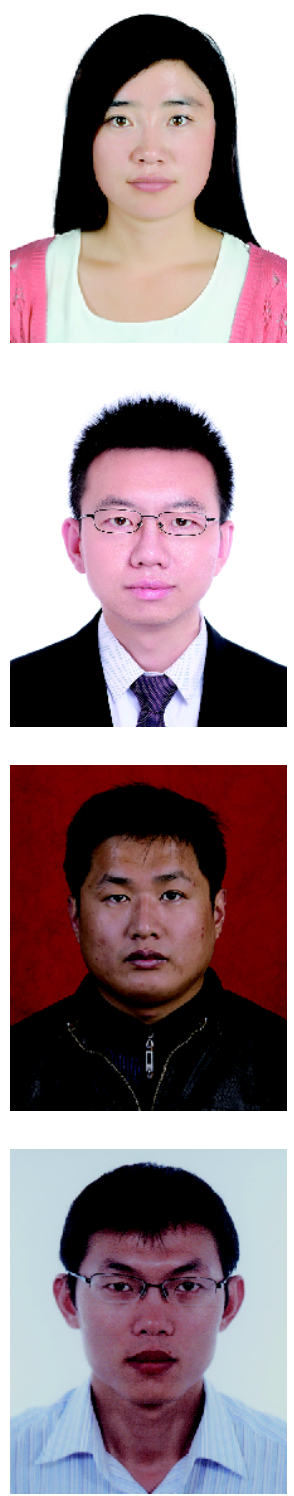

Jiamei Cao obtained her BSc degree from the Department of Northwest Normal University in 2014, and her MSc degree from Lanzhou Institute of Chemical Physics, Chinese Academy of Sciences, under the supervision of Prof. Hongguang Li, in July 2017. Her research interest is focused on microporous polymeric materials and functional fullerenes for applications in clean energy.
Yongqiang Feng obtained his BSc degree from Sichuan University in 2010 and $\mathrm{PhD}$ degree from the Institute of Chemistry, Chinese Academy of Sciences in 2015. After that, he joined Prof. Hongguang Li's group in Lanzhou Institute of Chemical Physics, Chinese Academy of Sciences as an assistant professor. Now, he is an associate professor in Shannxi University of Science \& Technology. His current interest is focused on the design of carbon-based nanomaterials for applications in optoelectronic devices.
Baoyong Liu obtained his BSc degree from Shandong University in 2003. And he received his Master's degree in chemical engineering from China University of Petroleum (East China) in 2008. He is currently a $\mathrm{PhD}$ candidate at Lanzhou Institute of Chemical Physics, Chinese Academy of Sciences under the supervision of Prof. Hongguang Li. His research interest includes carbon nanomaterials and tribology.

Hongguang Li obtained his BSc degree and PhD degree from Shandong University in 2003 and 2008, respectively. After three-year postdoc research, he joined the Laboratory of Clean Energy Chemistry and Materials, Lanzhou Institute of Chemical Physics, Chinese Academy of Sciences as a professor. His current interest focuses on the design of novel $\pi$ conjugated molecules and engineering carbon nanomaterials for the applications in optoelectronic devices.

\title{
掺杂钴、氮、硫、磷的碳骨架作为电化学析氧反应的高效催化剂
}

\author{
曹佳梅 ${ }^{1,2}$, 冯永强 ${ }^{1,3^{*}}$, 刘宝勇 ${ }^{1,2}$, 李洪光 ${ }^{1^{*}}$
}

摘要 本文提出了一种制备碱性介质中电化学析氧反应高效催化剂的新方法. 该方法选用一种含钴的碳一氮聚合物网络作为结构模板, 外 面包裏一层原位制备的、含硫和磷的超支化交联聚合物. $450^{\circ} \mathrm{C}$ 煅烧 $2 \mathrm{~h}$ 后, 获得可用于电化学析氧反应的、内部交联、微观呈现层状结 构的催化剂. 该催化剂在 $1.0 \mathrm{~mol} \mathrm{~L}^{-1}$ 的氢氧化钾水溶液中表现出很好的电化学催化活性和高稳定性. 电子衍射图谱(EDS)和X-射线光电子 能谱(XPS)研究表明该催化剂含有痕量钴及其他杂原子, 包括氮、硫、磷, 且证实了能够大幅提高催化活性的Co-N和Co-O活性物质的存 在. 将钴替换为铜和镍之后, 催化剂的催化活性大大降低, 表明当前方法对钴基催化剂的制备最为有效. 煅烧过程中所选用的温度对催化 剂的催化活性亦有显著影响, $450^{\circ} \mathrm{C}$ 为最优温度. 这些结果表明, 含钴的、杂原子(硫、磷)掺杂的碳氮化物有望成为一类新的电解水催化 剂, 以取代贵金属氧化物, 或作为其有益的补充. 